\title{
Article \\ Clinical Demonstrations of Controlled-Release Tablets Constructed by the Combined Usage of Shellac and Hydroxypropyl Methylcellulose
}

\author{
Junichiro Wakamatsu *D, Kanae Sato, Keisuke Uryu and Isafumi Maru \\ Research \& Development Division, Bizen Chemical Co., Ltd., 363 Tokutomi, \\ Akaiwa-shi 709-0716, Okayama, Japan; kanae-satou@bizen-c.co.jp (K.S.); \\ keisuke-uryuu@bizen-c.co.jp (K.U.); isafumi-maru@bizen-c.co.jp (I.M.) \\ * Correspondence: junichiro-wakamatsu@bizen-c.co.jp
}

check for updates

Citation: Wakamatsu, J.; Sato, K.; Uryu, K.; Maru, I. Clinical

Demonstrations of

Controlled-Release Tablets

Constructed by the Combined Usage of Shellac and Hydroxypropyl Methylcellulose. Future Pharmacol. 2021, 1, 48-59. https://doi.org/ 10.3390/futurepharmacol1010005

Academic Editor: Fabrizio Schifano

Received: 19 October 2021

Accepted: 11 November 2021

Published: 18 November 2021

Publisher's Note: MDPI stays neutral with regard to jurisdictional claims in published maps and institutional affiliations.

Copyright: (c) 2021 by the authors. Licensee MDPI, Basel, Switzerland. This article is an open access article distributed under the terms and conditions of the Creative Commons Attribution (CC BY) license (https:// creativecommons.org/licenses/by/ $4.0 /)$.

\begin{abstract}
A new tablet system was examined for an intestinal delivery system using hydroxypropyl methylcellulose (HPMC) and shellac. HPMC was incorporated into the inside of the tablet, and shellac was coated on the surface, which was evaluated for its controlled-release property through several dissolution tests, firstly in vitro and then via two kinds of clinical studies with healthy volunteers. The clinical studies were originally designed by employing $\mathrm{X}$-ray photography for the movements of the tablets in the gastrointestinal tract and an electronical device to easily analyze the absorption profile of glucose, a model compound. It was found that the dissolution of the tablet was strongly suppressed in a simulated gastric fluid ( $\mathrm{pH}$ 1.2) and subsequently started to disintegrate in a simulated intestinal fluid ( $\mathrm{pH}$ 6.8). The first human study with $\mathrm{X}$-ray photography revealed that the model tablets could pass through the stomach without disintegrating. The controlled release of the tablets was further confirmed via analyses of the AUC, $C_{\max }$, and $\mathrm{T}_{\max }$ for the blood glucose concentration with other volunteers. The AUC and $C_{\max }$ were significantly reduced by using our system, thus concluding that the delivery system combined with the addition of HPMC and a shellac coating unequivocally leads to controlled release in the human gastrointestinal tract.
\end{abstract}

Keywords: intestinal delivery; controlled release; hydroxypropyl methylcellulose; shellac; X-ray

\section{Introduction}

The novel severe acute respiratory syndrome coronavirus 2 (SARS-CoV-2) pandemic has caused drastic changes in our lives, such as national lockdowns across the world, social distancing, wearing face coverings, etc., as well as a focus on changing our habits to maintain healthy lifestyles. According to global market analysis [1], there is a major interest in immunity-boosting supplements, such as vitamins, minerals, and herbs, and, in particular, commercial products containing a unique Lactobacillus strain, Lactococcus lactis strain Plasma, which are at the center of public attention in Japan [2]. Some molecular-docking studies have implied that rutin and hesperidin might act as inhibitors through binding the main SARS-CoV-2 protease, with higher affinity than the commercially available antiviral drugs ritonavir and indinavir [3]. This may encourage healthcare industries to develop anti-COVID-19 supplements until the vaccines reach everyone in the world. The market size for dietary supplements, which was valued at USD 140.3 billion in 2020, is expected to expand with a compound annual growth rate of 8.6\% from 2021 to 2028 [1], indicating that dietary supplements will become much more important in the future.

Tablets are the most popular dosage form in the world, as shown by market analysis [1], because of the ease of their ingestion without undesirable tastes from the ingredients, easy transportation with a compact and robust structure, and relatively low preparation costs. Tableting technology is evolving with chemically synthesized polymers. In pharmaceutical industries, methacrylic acid copolymers, hydroxypropyl methylcellulose phthalate, and ethyl cellulose are used as coating substitutes to obtain controlled-release 
tablets that disintegrate after passing through the stomach [4-6]. Carboxyvinyl polymer, polyvinylpyrrolidone, and hydroxypropyl methylcellulose (HPMC) have been added, resulting in matrix-type tablets for sustained release, which dissolve very slowly after ingestion $[7,8]$. The characteristics of sustained or controlled release improve the bioavailability of compounds with short elimination half-lives, e.g., acetaminophen and diclofenac $[9,10]$, and they are adopted for many commercial drugs to reduce the number of daily doses required. Since the use of such additives is prohibited in food supplements in several regions, including the United States, Japan, and the EU, food industries have made great efforts towards developing a modified-release tablets. Phaechamud et al. [11] reported that a matrix-type tablet containing chitosan and xanthan gum, which is available as a food supplement, showed sustained release in vitro, but the tablet system was too low to handle commercially. Maity et al. [12] found that a coating technique using xanthan gum and sodium alginate created a controlled-release film that did not dissolve in a simulated gastric fluid. However, this study lacked demonstrations in vivo, and its practicability is still unclear. Consequently, a gastrointestinal delivery system using food-grade additives has not yet been established.

HPMC is an additive available for use in medicine and food. Its structure consists of a mixed alkyl hydroxyalkyl cellulose ether with methoxy and hydroxypropyl groups, the rate of hydration of which depends on the molecular structure and degree of substitution. The hydration rate increases with the amount of hydroxypropyl, which can slowly dissolve in cold water, as it is a viscous solution. By utilizing these characteristics, HPMC was incorporated into the inside of a tablet for sustained-release systems, the efficacy of which was supported by several studies in vitro and in vivo $[9,13,14]$. However, it has not yet been reported whether the HPMC-containing tablets reached the lower-intestinal sites between the ileum and colon. As indicated by Naggar et al. [15], not only HPMC but also a coating technology that protects the tablet from releasing its ingredients in the upper intestine upon exposure to gastric fluid would be necessary for effective gastrointestinal delivery. Shellac is permitted for use in food as a coating material. It is a natural material secreted by the small insect Kerria Lacca on various host trees in Southeast Asia, and is a mixture of esters of aleuritic acid, butolic acid, jalaric acid, and shellolic acid. As shellac is soluble in conditions above $\mathrm{pH} 7.3$, it was investigated as an enteric coating material [16-18], but its actual performance in humans had not yet been demonstrated.

The present study was therefore conducted to obtain an optimal formula for enteric and controlled-release tablets using HPMC and shellac, by means of in vitro dissolution studies, and to clinically demonstrate their intestinal delivery functions through qualitative and quantitative approaches with human volunteers. The data obtained constitute new evidence in the literature for an intestinal delivery system using a combined formula.

\section{Materials and Methods}

\subsection{Materials and Chemicals}

Crystalline cellulose (VIVAPUR101), lactose (Lactose-100M), calcium stearate, and HPMC (SE-06 and NE4000) were purchased from JRS Pharma (Tokyo, Japan), Glanbia Ireland (Kilkenny, Ireland), EIKA Corporation (Tokushima, Japan), and Shin-Etsu Chemical (Tokyo, Japan), respectively. Maltitol (Amalty-MR50) and sorbitol (Sorbit) were commercially obtained from Mitsubishi Corporation Life Sciences (Tokyo, Japan). Sucrose fatty acid ester (S-570) was purchased from Mitsubishi Chemical Cooperation (Tokyo, Japan). Starch (Perfiller102) and 10\% $(w / w)$ shellac solution (AQ shellac) were purchased from FREUND CORPORATION (Tokyo, Japan). Agar (disintegration grade), silicon dioxide (Sylopage), and psyllium husk powder were bought from Ina Food Industry (Nagano, Japan), Fuji Silysia Chemical (Aichi Japan), and Shikibo Cooperation (Osaka, Japan), respectively. All the additives used were food grade. A red-coloring agent (Allura Red AC) was obtained from San-Ei Gen F.F.I., Inc (Osaka, Japan). Hydrogen chloride, sodium chloride, sodium hydroxide, and potassium dihydrogen phosphate were commercially obtained from KANTO CHEMICAL CO., INC (Tokyo, Japan). 


\subsection{Formulation of Controlled-Release Tablets and Study of Their Dissolution In Vitro}

Tablet systems with the formulas shown in Table 1 were examined. Granulated lactose, starch, and maltitol, which are well-used excipients, were utilized. Additionally, calcium stearate and HPMC were added as a lubricant and gelling agent, respectively. Allura red AC was incorporated into each formula for the dissolution studies, and then the total weights of the formulas were maintained by adjustment when the amount of lactose was changed. All materials were mixed for one minute in laboratory plastic bags by hands at each batch size of $1500 \mathrm{~g}$. Tableting was performed by employing a laboratory tableting machine (clean press correct 19K, KIKUSUI SEISAKUSHO LTD, Kyoto, Japan), which was equipped with round-shaped punches and dies of $\varphi 9 \mathrm{~mm}$. The operating conditions were as follows; compression force: $1.0-1.2 \mathrm{kN}$; rotation speed: $35 \mathrm{rpm}$. Thereafter, the five kinds of tablets were individually coated using a laboratory coating machine (DRIACOATOR DRC-500, Powlex, Hyogo, Japan) until the average weights reached $357 \mathrm{mg} /$ tablet. The coating layer was composed of shellac, sorbitol, and sucrose fatty acid ester (S-570) at a weight ratio of 5:1:1 with common conditions as follows: batch size: $1500 \mathrm{~g}$; inlet temperature: $65-70{ }^{\circ} \mathrm{C}$; outlet temperature: $50-53{ }^{\circ} \mathrm{C}$; air flow: $3.5 \mathrm{Nm}^{3} / \mathrm{min}$; atomizing air: $60 \mathrm{~L} / \mathrm{min}$; spray feed rate: approx. $50 \mathrm{~g} / \mathrm{min}$; pan revolutions: $13-14 \mathrm{rpm}$; diameter of spray nozzle: $1 \mathrm{~mm}$.

Table 1. Formulas of tested tablets from No.1 to No.5.

\begin{tabular}{cccccc}
\hline & $\begin{array}{c}\text { Tablet } \mathbf{1} \\
{[\%]}\end{array}$ & $\begin{array}{c}\text { Tablet 2 } \\
{[\%]}\end{array}$ & $\begin{array}{c}\text { Tablet 3 } \\
{[\%]}\end{array}$ & $\begin{array}{c}\text { Tablet 4 } \\
{[\%]}\end{array}$ & $\begin{array}{c}\text { Tablet 5 } \\
{[\%]}\end{array}$ \\
\hline maltitol & 50.0 & 50.0 & 50.0 & 50.0 & 50.0 \\
lactose & 33.5 & 28.5 & 23.5 & 18.5 & 13.5 \\
starch & 10.0 & 10.0 & 10.0 & 10.0 & 10.0 \\
HPMC & 0.0 & 5.0 & 10.0 & 15.0 & 20.0 \\
calcium stearate & 3.0 & 3.0 & 3.0 & 3.0 & 3.0 \\
coloring agent * & 3.5 & 3.5 & 3.5 & 3.5 & 3.5 \\
total & 100.0 & 100.0 & 100.0 & 100.0 & 100.0 \\
\hline
\end{tabular}

HPMC: hydroxypropyl methylcellulose; *: Allura red AC was used as the coloring agent. Each tableting was performed at a weight of $330 \mathrm{mg}$, followed by the coating process with water-soluble shellac.

The dissolution profiles of the tablets were evaluated in vitro by means of a dissolution test in accordance with Japanese Pharmacopoeia (17th edition). Briefly, a dissolution tester (NTR-3000, Toyama Sangyo Co., Ltd., Osaka, Japan) was used; the paddle rotations and the temperature of the tested fluids were set at $50 \mathrm{rpm}$ and $37^{\circ} \mathrm{C}$, respectively. The test fluids were JP1 fluid ( $\mathrm{pH}$ 1.2) for a model of gastric liquid, which was composed of $2 \mathrm{~g} / \mathrm{L} \mathrm{NaCl}$ and $7 \mathrm{~mL} / \mathrm{L} \mathrm{HCl}$, and JP2 fluid ( $\mathrm{pH}$ 6.8) for a model of gastrointestinal fluid, prepared from a mixture of $0.05 \mathrm{~mol} / \mathrm{L} \mathrm{KH}_{2} \mathrm{PO}_{4}$ and $23.6 \mathrm{mmol} / \mathrm{L} \mathrm{NaOH}$. A tablet of each formula prepared was added in the JP1 fluid for two hours at first; then, it was immediately moved to the JP2 fluid and tested for nine hours. Sampling $(5 \mathrm{~mL})$ was performed at regular intervals, and fresh fluids heated to $37^{\circ} \mathrm{C}$ were supplied each time to maintain the total volume at $1000 \mathrm{~mL}$. After the filtration of the samples, their absorbances at $510 \mathrm{~nm}$ were measured to detect the Allura red AC eluted from each tablet, employing a spectrophotometer (U2900, HITACHI, Tokyo, Japan). The dissolution rates of the tablets were calculated with a standard curve given by several concentrations of Allura red AC diluted in the JP2 fluid.

Kinetic analysis was performed for the five kinds of systems using the following equations:

Zero-order equation:

$$
\mathrm{Q}_{\mathrm{t}}=\mathrm{K}_{0} t \text {, }
$$

where $\mathrm{Q}_{\mathrm{t}}$ is the amount of Allura red $\mathrm{AC}$ released in time $t$, and $\mathrm{K}_{0}$ represents the zero-order release rate constant.

First-order equation:

$$
\mathrm{Q}_{\mathrm{t}}=\mathrm{Q}_{0} \cdot \mathrm{e}^{-\mathrm{K} 1 \mathrm{t}},
$$


where $Q_{t}$ is the amount of Allura red AC released in time $t, Q_{0}$ is the initial amount of the coloring agent, and $\mathrm{K}_{1}$ represents the first-order release rate constant.

Korsmeyer-Peppas equation:

$$
\mathrm{Q}_{\mathrm{t}} / \mathrm{Q}_{\infty}=\mathrm{K}_{\mathrm{kp}} \cdot t^{\mathrm{n}}
$$

where $Q_{t} / Q_{\infty}$ is the cumulative release ratio of the Allura red $A C$ released at time $t$, and $\mathrm{K}_{\mathrm{kp}}$ represents the release rate constant. The $\mathrm{n}$ value is used to characterize different release mechanisms.

2.2.1. Preparation of X-ray Absorbable Controlled-Release Tablets with Barium Sulfate and Study of Their Dissolution In Vitro

Unique tablets that were visually detectable under X-ray exposure were formulated using barium sulfate (baribriteLV, Kaigen pharma Co., Ltd., Osaka, Japan). With a batch size of $1500 \mathrm{~g}$, the six formulas shown in Table 2 were tableted in the same way as described above, and their weights were controlled to be approx. $683.4 \mathrm{mg} /$ tablet. Tablets $6 \mathrm{a}$ and $6 \mathrm{~b}$ were not coated, and tablets $7 \mathrm{a}, 7 \mathrm{~b}, 8 \mathrm{a}$, and $8 \mathrm{~b}$ were coated with shellac solutions, for which $50 \mathrm{~g}$ of sorbitol, $50 \mathrm{~g}$ of sucrose fatty acid ester, and/or $117 \mathrm{~g}$ of HPMC (SE-06) were dissolved in a $2500 \mathrm{~g}$ shellac solution, using the same instrument and conditions as described above. The coating process was finished when the average weight of each tablet reached $731.2 \mathrm{mg}$. Next, tablets $6 \mathrm{a}, 7 \mathrm{a}$, and $8 \mathrm{a}$ were used for dissolution tests, the details of which are mentioned above, and tablets $6 \mathrm{~b}, 7 \mathrm{~b}$, and $8 \mathrm{~b}$ were subjected to a human volunteer study described below.

Table 2. Formulas of barium sulfate-containing tablets $6 a, 6 b, 7 a, 7 b, 8 a$, and $8 b$.

\begin{tabular}{ccccccc}
\hline & $\begin{array}{c}\text { Tablet 6a } \\
{[\%]}\end{array}$ & $\begin{array}{c}\text { Tablet 6b } \\
{[\%]}\end{array}$ & $\begin{array}{c}\text { Tablet 7a } \\
{[\%]}\end{array}$ & $\begin{array}{c}\text { Tablet 7b } \\
{[\%]}\end{array}$ & $\begin{array}{c}\text { Tablet 8a } \\
{[\%]}\end{array}$ & $\begin{array}{c}\text { Tablet 8b } \\
{[\%]}\end{array}$ \\
\hline Barium sulphate & 65.0 & 65.0 & 65.0 & 65.0 & 65.0 & 65.0 \\
Crystalline cellulose & 28.5 & 32.0 & 23.5 & 27.0 & 18.5 & 22.0 \\
Agar & 0.0 & 0.0 & 5.0 & 5.0 & 0.0 & 0.0 \\
Psyllium husk powder & 0.0 & 0.0 & 0.0 & 0.0 & 0.5 & 0.5 \\
HPMC & 0.0 & 0.0 & 0.0 & 0.0 & 9.5 & 9.5 \\
Silicon dioxide & 2.0 & 2.0 & 2.0 & 2.0 & 2.0 & 2.0 \\
Calcium stearate & 1.0 & 1.0 & 1.0 & 1.0 & 1.0 & 1.0 \\
Coloring agent * & 3.5 & 0.0 & 3.5 & 0.0 & 3.5 & 0.0 \\
Total & 100.0 & 100.0 & 100.0 & 100.0 & 100.0 & 100.0 \\
\hline
\end{tabular}

HPMC: hydroxypropyl methylcellulose; *: Allura red AC was used as the coloring agent. Each tableting was performed at a weight of $683 \mathrm{mg}$, followed by the coating process with water-soluble shellac except for tablets 6a and $6 \mathrm{~b}$.

2.2.2. Human Volunteer Study with Barium-Containing Tablets by Means of X-ray Photography

The protocol used in this study was approved by a research ethics committee (application number: ULS202003, 2020), which was organized by User Life Science Co., Ltd., (Fukuoka, Japan), and the whole study was conducted in the Takahira internist clinic under proper doctor's advice. Written informed consent was obtained from all the participants in accordance with the Helsinki Declaration revised in Fortaleza, Brazil, 2013. Three healthy volunteers (20-28 years old; male only) were selected for this study after giving informed written consent. They had fasted without drinking from 21:00 on the day before the study, and then, tablets $6 \mathrm{~b}, 7 \mathrm{~b}$, and $8 \mathrm{~b}$ were administrated to each person with $150 \mathrm{~mL}$ of water in the morning from 6:30 to 9:00. They rested calmly until 12:30; in the meantime, X-ray scans were performed four times. The $\mathrm{X}$-ray examinations were strictly restricted to a maximum of four times a day because of radiation exposure. 


\subsection{Preparation of Controlled-Release Tablets Containing Glucose and Quantitative Demonstration with Human Volunteers}

Three compositions were formulated using glucose as an indicator for absorption in the upper gastrointestinal tract (Table 3). These tablets were also prepared in the same way as described above, with weights of about $452.25 \mathrm{mg}$. Afterwards, tablets 10 and 11 were coated, employing shellac solutions consisting of $250 \mathrm{~g}$ of shellac, $50 \mathrm{~g}$ of sorbitol, $50 \mathrm{~g}$ of sucrose fatty acid ester, and $117 \mathrm{~g}$ of HPMC, using the same instrument and conditions as described above, which resulted in coated tablets with weights of approximately $483.84 \mathrm{mg}$, respectively.

Table 3. Compositions of glucose-containing tablets 9,10 , and 11.

\begin{tabular}{|c|c|c|c|}
\hline & $\begin{array}{l}\text { Tablet } 9 \\
\text { (mg) }\end{array}$ & $\begin{array}{l}\text { Tablet } 10 \\
\text { (mg) }\end{array}$ & $\begin{array}{l}\text { Tablet } 11 \\
\text { (mg) }\end{array}$ \\
\hline Glucose & 402.75 & 402.75 & 402.75 \\
\hline Crystalline cellulose & 33.75 & 20.25 & 0.00 \\
\hline Psyllium husk powder & 0.00 & 2.25 & 2.25 \\
\hline HPMC & 0.00 & 13.50 & 33.75 \\
\hline Calcium stearate & 13.50 & 13.50 & 13.50 \\
\hline Total & 450.00 & 452.25 & 452.25 \\
\hline
\end{tabular}

HPMC: hydroxypropyl methylcellulose; tablets 10 and 11 were coated with water-soluble shellac.

These tablets were subjected to another human volunteer study, the protocol of which was approved by the ethics committee (application number: ULS202101, 2021), and this study was executed in a double-blinded manner. Providing informed consent through documentation, eleven healthy volunteers (26-58 years old; two females and nine males) were entered for this study. A commercially available device, namely, FreeStyle Libre (Abbott, Japan), was used to automatically monitor their blood glucose levels; moreover, it was used to exclude diabetic people with fasting blood glucose concentrations higher than $120 \mathrm{mg} / \mathrm{dL}$. The participants had fasted without drinking since 21:00 the day before the study and attached the devices by themselves during that night, and then, tablets 9 , 10, and 11 were administrated to each person with $200 \mathrm{~mL}$ of water the next morning from 6:00 to 8:00. Each study finished when five hours had passed, during which blood glucose levels were recorded every thirteen minutes. The individual data were adjusted by subtracting each baseline value, which was given by the average scores for thirty minutes before starting the ingestions; then, the delta glucose area under the concentration versus time curve for $180 \mathrm{~min}\left(\triangle \mathrm{AUC}_{0-180}\right)$ was calculated, as well as the $\mathrm{C}_{\max }$ and $\mathrm{T}_{\max }$.

\subsection{Statistical Data Analysis}

All the data obtained from the human study were statistically analyzed using Microsoft Excel (windows 2020) with an add-in (Bellcurve for Excel ver3.0) to perform one-way analysis of variance (ANOVA), followed by the Bonferroni test for multiple comparisons. Differences in values were considered to be significant when the $p$ value was less than 0.05 .

\section{Results and Discussion}

\subsection{Formulation and Characterization of Controlled-Release Tablets Using HPMC and Shellac}

Maltitol and lactose were used as excipients, starch was used as a disintegrant, and calcium stearate was used as a lubricant to formulate controlled-release tablets with different ratios of HPMC (Table 1). As every formula showed good flowability, they were compressed without granulation processes, which resulted in well-molding tablets with a weight of $330 \pm 3 \mathrm{mg}$ ( $\varphi 9 \mathrm{~mm}$ ), with hardness ranging from 8 to $10 \mathrm{kgf}$. In order to add an enteric property to the tablets, shellac solution mixed with plasticizers was utilized for the coating process. The dissolution profiles of the tablets coated were evaluated through sequential dissolution tests using JP1 and JP2 fluids based on a report [4], an assessment mimicking exposure to the human gastrointestinal tract. Focusing on the changes in absorbance at $510 \mathrm{~nm}$ derived from the red-coloring agent, the dissolution profiles of each 
formula were revealed (Figure 1). No elution of the red pigment was observed in the JP1 fluid, whereas the color was gradually released from all the tablets in the JP2 fluid.

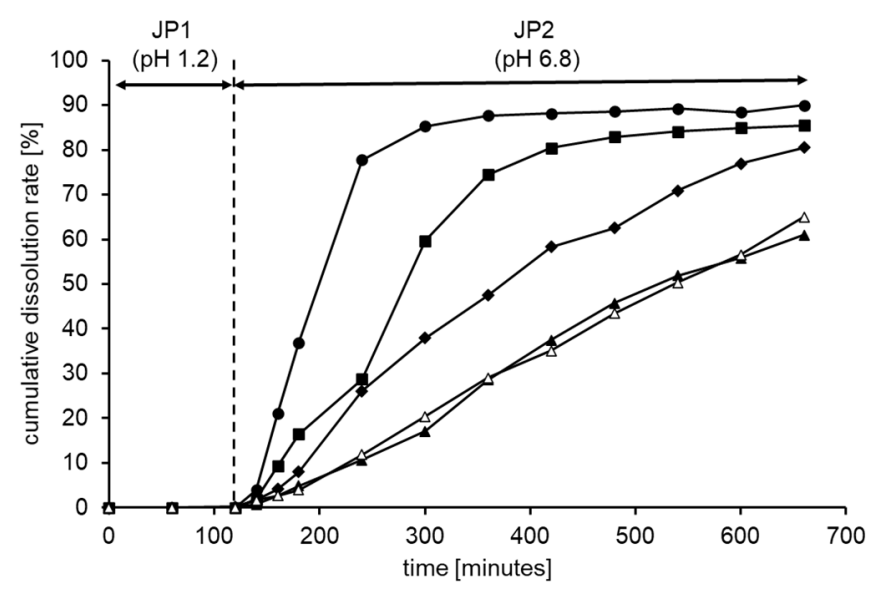

Figure 1. Red-pigment release profiles of tablet 1 (closed circle), tablet 2 (closed square), tablet 3 (closed diamond), tablet 4 (closed triangle), and tablet 5 (opened triangle) in in vitro dissolution tests using the JP1 fluid for the first $120 \mathrm{~min}$, followed by the JP2 fluid elution until $660 \mathrm{~min}$. This experiment was repeated twice, and each data point represents the average of duplicated tests.

In order to determine the release mechanisms for the tablets tested, kinetic analyses were performed, employing the Korsmeyer-Peppas model, and zero-order and first-order equations (Table 4). The Korsmeyer-Peppas model is suitable for analyzing release from matrix systems containing swelling and non-swelling polymers, and $\mathrm{n}$ is the release exponent indicative for the mechanism of the transport of ingredients through the polymer [19]. Among the three regressions, the Korsmeyer-Peppas model showed the best fitting because the $\mathrm{R}^{2}$ values were more than 0.9 . The $\mathrm{n}$ values calculated by the model were $>1.0$, indicating that the release mechanism would be relaxation and/or erosion for the tablet systems without Fickian diffusional release due to a chemical potential gradient [20]. Actually, all the tablets except tablet 1 gradually swelled from water penetration, and the appearance varied, with the tablets becoming about twice as large; therefore, the relaxation of the structure would be the main mechanism of release. From the changes in the rate constants from all the regressions, it was found that 15\% HPMC was enough to add for controlled release. On the other hand, the release profiles obtained for tablets 4 and 5 need to be investigated for commercial utilization from the point of view of oral absorbability. He et al. [14] revealed that sustained-release tablets containing metformin and repaglinide showed bioavailabilities equal to those of rapid-release tablets in in vivo studies with beagle dogs. Metformin and repaglinide are used for models of water-soluble and poorly water-soluble drug compounds, respectively; the sustained-release tablets exhibited release profiles similar to our data obtained in vitro. This comparison shows a possibility that our formulas such as tablets 4 and 5 might serve as drug compounds that are widely absorbable in the gastrointestinal tract, while food components that are mainly absorbed in the upper intestine, such as sugars and amino acids, may inhibit their absorbability.

Shellac is a pH-responsive wax material, and it does not dissolve at $\mathrm{pH} 1.2$ (JP1 fluid), functioning as a shield for gastric fluid. This is why each tablet did not release any red pigments in the first $120 \mathrm{~min}$. On the other hand, the optimal $\mathrm{pH}$ for the dissolution of shellac is about 7.3 [21], and there is a notable difference from the $\mathrm{pH}$ of the JP2 fluid, indicating that the coating layer of each formula would not be dissolved, but would swell in the dissolution test. The swelling weakened the barrier function of the coating layer, and water penetrated into the tablet's core. Since the profile of tablet 1 is in line with the literature [17], the swelling phenomenon makes sense. When water molecules contact the HPMC in the tablets, highly viscous sol layers are formed, which inhibit erosion. Hence, the dissolution rates were reduced with an increase in the content of HPMC, and such a 
tendency was well-observed in another study [22]. Known food-grade delivery systems constructed from xanthan gum mixed with sodium alginate or xanthan gum with chitosan showed faster release profiles than our system [11,12]. Additionally, Naggar et al. [15] revealed that a pharmaceutical coating employing methacrylic acid copolymer did not inhibit flowing out at all, and blend coatings with ethyl cellulose, sodium alginate, or sodium carboxymethyl cellulose strongly suppressed drug release in a $\mathrm{pH} 6.8$ solution. These data indicate that our tablet system combined with the shellac coating and the use of HPMC inside possesses an advantage in controlled release compared to known food-grade technologies, though it does not achieve the level of control obtained using pharmaceutical additives.

Table 4. Results of kinetic analyses for tablets 1, 2, 3, 4, and 5.

\begin{tabular}{cccccccc}
\hline & \multicolumn{2}{c}{ Zero-Order } & \multicolumn{2}{c}{ First-Order } & \multicolumn{3}{c}{ Korsmeyer-Peppas } \\
\cline { 2 - 8 } & $\mathbf{K}_{\mathbf{0}}$ & $\mathbf{R}^{\mathbf{2}}$ & $\mathbf{K}_{\mathbf{1}}$ & $\mathbf{R}^{\mathbf{2}}$ & $\mathbf{n}$ & $\mathbf{K}_{\mathbf{k p}}$ & $\mathbf{R}^{\mathbf{2}}$ \\
\hline Tablet 1 & 2.682 & 0.856 & 0.264 & 0.939 & 1.64 & 0.310 & 0.959 \\
Tablet 2 & 1.556 & 0.910 & 0.134 & 0.962 & 1.40 & 0.124 & 0.968 \\
Tablet 3 & 1.098 & 0.965 & 0.082 & 0.997 & 1.30 & 0.080 & 0.991 \\
Tablet 4 & 0.855 & 0.990 & 0.049 & 0.990 & 1.30 & 0.042 & 0.993 \\
Tablet 5 & 0.861 & 0.999 & 0.050 & 0.982 & 1.18 & 0.051 & 0.991 \\
\hline
\end{tabular}

$\mathrm{K}_{0}, \mathrm{~K}_{1}$, and $\mathrm{K}_{\mathrm{kp}}$ are rate constants for zero-order, first-order, and Korsmeyer-Peppas, respectively; $\mathrm{R}^{2}$ is the correlation coefficient; $\mathrm{n}$ is the release exponent.

\subsection{Photographical Demonstration of Gastrointestinal Delivery System Using X-ray Absorbable Barium}

In order to demonstrate the controlled-release character of the tablet system in vivo, movements of the tablet in the gastrointestinal tract of humans were photographically evaluated using X-rays. As food excipients are not visible in X-ray films, barium sulfate was added for the tablet system. Then, six kinds of tablets were prepared (see Table 2), followed by coating with the same conditions as mentioned as above except for tablets $6 \mathrm{a}$ and $6 \mathrm{~b}$. Their weights were similar, and the hardness did not significantly differ, ranging from 7 to $9 \mathrm{kgf}$. Before the human volunteer study, the sustainable-release ability of the specially prepared tablets containing barium sulfate was verified through in vitro dissolution tests with the JP2 fluid. As shown in Figure 2, tablet 6a, non-coated, showed the fastest dissolution, which reached $80 \%$ in $240 \mathrm{~min}$. Tablets $7 \mathrm{a}$ and $8 \mathrm{a}$ coated with shellac exhibited slower release of the red pigment than tablet $6 \mathrm{a}$, and in particular, the addition of $10 \%$ HPMC delayed the dissolution. Although the dissolution tests were performed without the JP1 fluid, the dissolution tendency seemed similar to that shown in Figure 1, implying that this set of barium-containing tablets would be useful for demonstrating the gastrointestinal delivery system by $\mathrm{X}$-ray photography.

Tablets $6 \mathrm{~b}, 7 \mathrm{~b}$, and $8 \mathrm{~b}$, which were the same in composition as $6 \mathrm{a}, 7 \mathrm{a}$, and $8 \mathrm{a}$ without the red pigment, were administered to three healthy volunteers. The timing of the $\mathrm{X}$-ray films was adjusted through some trials following the protocol, which resulted in 30, 90, and $180 \mathrm{~min}$ for tablet $6 \mathrm{~b} ; 180,240$, and $300 \mathrm{~min}$ for tablet $7 \mathrm{~b}$; and 30, 90, and $300 \mathrm{~min}$ for tablet $8 \mathrm{~b}$ (Figure 3). Uncoated tablet $6 \mathrm{~b}$ rapidly disintegrated in the stomach after $90 \mathrm{~min}$ (A-1, A-2, and A-3), while tablet 7b coated with shellac without HPMC remained intact in shape for $180 \mathrm{~min}$, followed by disintegration by the next shutter point (B-1, B-2, and B-3). Regarding the doctor's opinion, it was expected that the disintegration of tablet $7 \mathrm{~b}$ would begin in the upper intestine, not the stomach. Although zip fasteners and buttons of the trousers of the volunteer appeared in the films of B as artifacts, these did not interfere with our analysis. Additionally, the addition of HPMC extraordinarily prolonged the tablet's life, and the round shape was clearly observed after $300 \mathrm{~min}$ from ingestion (C-1, C-2, and C-3). According to both in vitro and in vivo data, $80 \%$ of tablet 7 a was dissolved in JP2 fluid by $300 \mathrm{~min}$. However, the tablet was exposed to neutral conditions in the gastrointestinal tract for less than $300 \mathrm{~min}$ in the human study, and it disappeared. Koziolek et al. [23] mentioned 
that the $\mathrm{pH}$ values in the gastric tracts of healthy volunteers were observed to be as follows; stomach: one to eight; small intestine in proximal region: around six; small intestine in distal areas: seven to eight; colon: five to eight. They pointed out that the ingestion of a tested material with water after fasting could cause an increase in the intragastric $\mathrm{pH}$ due to oral secretions. Therefore, it was deduced that our shellac coating might have been partially dissolved or become greatly swollen in the stomach, followed by the slightly earlier destruction of the tablet. From these considerations, this study confirmed that the shellac coating as well as HPMC addition would need to extend the delivery distance, and the delivery was further demonstrated by means of another human study.

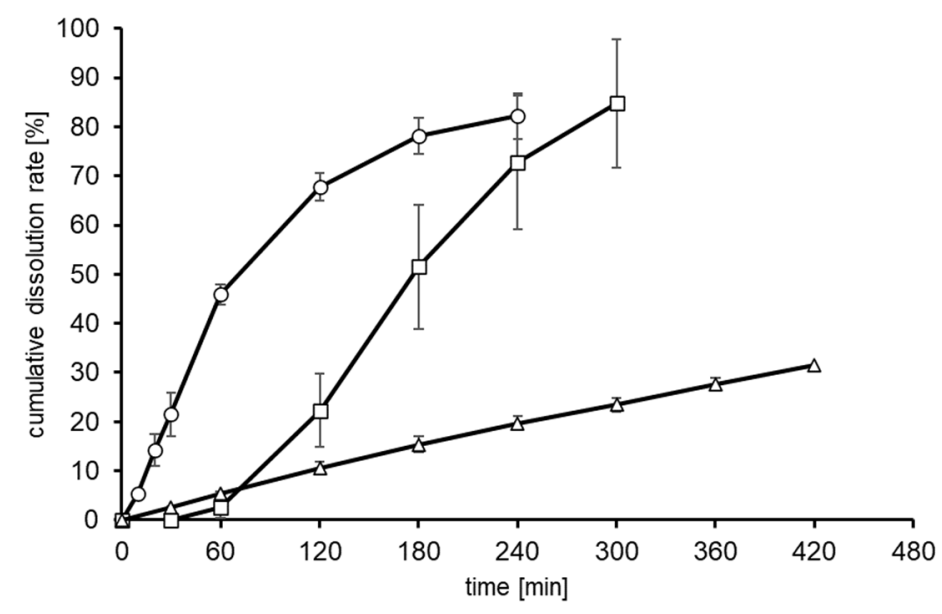

Figure 2. In vitro dissolution tests of tablets 6a (open circles), 7a (open squares), and 8a (open triangles) with JP2 fluid. Data represent means \pm SDs $(n=3)$.

\subsection{Quantitative Demonstration of Gastrointestinal Delivery System by Blood Glucose Concentration}

In addition to the photographical demonstration, the gastrointestinal delivery of our tableting system was further proved by focusing on the blood glucose levels of healthy volunteers. Three types of tablets were formulated for the ingestion of $10 \mathrm{~g}$ of glucose per twenty-five tablets (see Table 3). Each tablet possessed enough hardness, more than $10 \mathrm{kgf}$, and was coated with shellac in the same way as described above. The monitoring device, the Freestyle Libre, is utilized worldwide for diabetes patients to monitor the glucose concentration in cell interstitial fluid, the values of which have been verified to be equivalent to the blood glucose level by a clinical study [24]. Before starting the human study, preliminarily monitoring the glucose levels for the participants revealed that a person was outside the healthy criteria, so they were excluded. After the end of the study, one device for a person was found not to be working correctly. Hence, the data of nine people were selected for the analyses.

Although all the volunteers were healthy, without diabetic symptoms, their baseline glucose levels were quite different in the morning. Therefore, we needed to control for the individual differences through calculating delta values in this study. The changes in the delta glucose concentration (actual glucose concentration-baseline level) are compiled in Figure 4, and the $\mathrm{AUC}_{0-180 \min }, \mathrm{C}_{\max }$, and $\mathrm{T}_{\max }$ values are shown in Table 5 . Three similar peaks were found, as shown in Figure 4, with quite different intensities in the order of tablet $9>$ tablet $10>$ tablet 11 . The $\mathrm{AUC}_{0-180 \mathrm{~min} S}$ of tablets 10 and 11 were significantly decreased compared to the $\mathrm{AUC}_{0-180 \mathrm{~min}}$ of tablet 9 , and the average value for tablet 11 was lower than that for tablet 10, without significant differences $(p=0.184)$. This tendency was also shown in the data of the $C_{\max }$ values, whereas no differences were found for $\mathrm{T}_{\max }$. Wachters-Hagedoorn et al. [25] showed that the changing of the blood glucose concentration in healthy people ended within two hours after glucose ingestion, and the profile agreed well with that in the present study, as did the average $T_{\max }$ values. Tablets containing HPMC and coated with shellac exhibited reduced $C_{\max }$ values, which would 
contribute to decreases in the AUC values, and it was deduced that the glucose release from tablets 10 and 11 was suppressed by factors of 0.61 and 0.32 vs that from tablet 9 . Taking both volunteer studies into consideration, it can be concluded that our tablet system certainly controls ingredient release in the gastrointestinal tract.
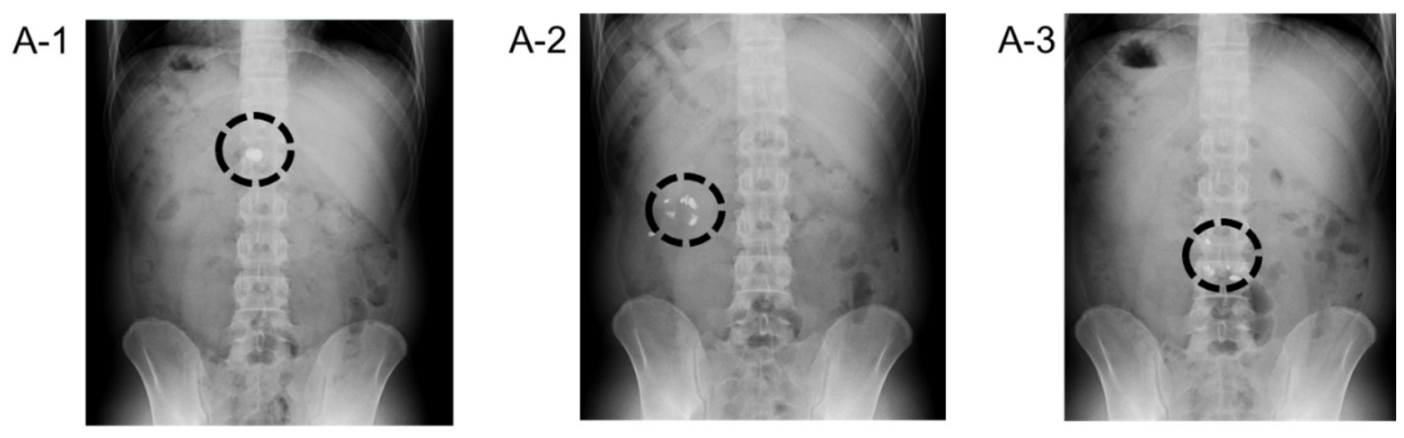

B-1
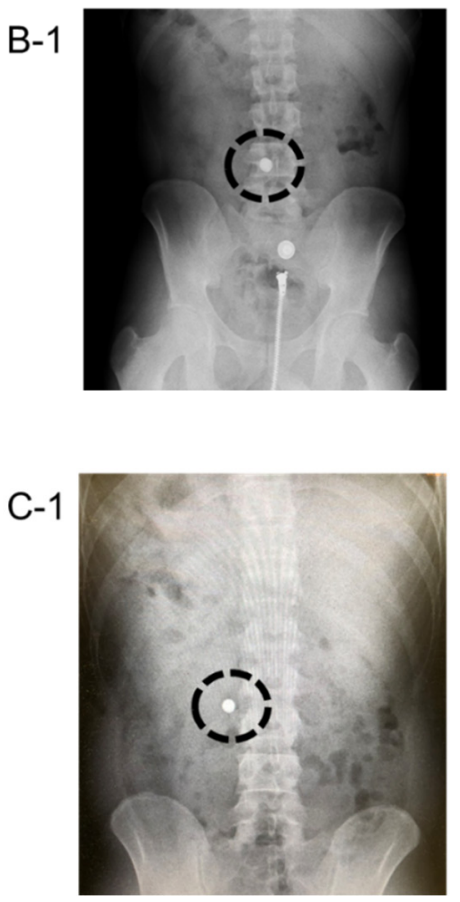

B-2

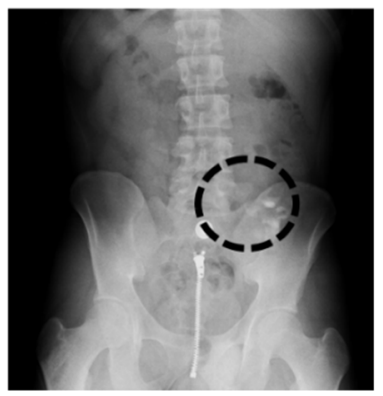

C-2

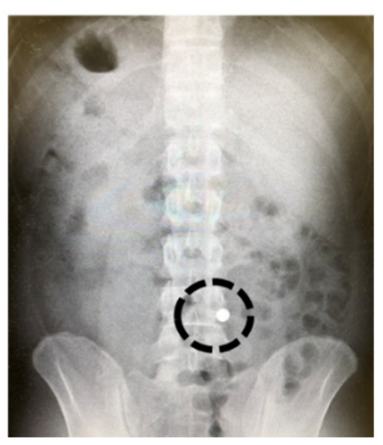

B-3

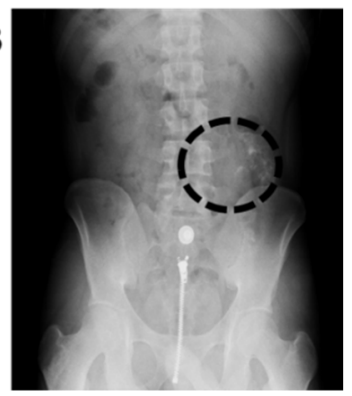

C-3

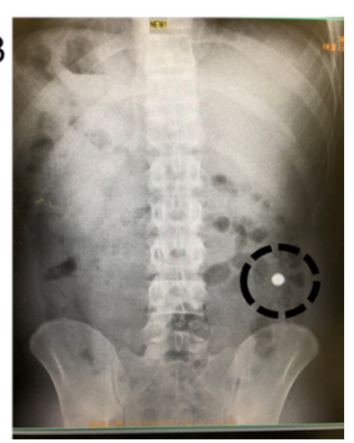

Figure 3. X-ray photographical analysis of tablets $6 \mathrm{~b}, 7 \mathrm{~b}$, and $8 \mathrm{~b}$ with healthy volunteers. A-1 (30 min), A-2 (90 min), and A-3 (180 min) were taken from tablet $6 \mathrm{~b}$; B-1 (180 min), B-2 (240 min), and B-3 (300 min) were taken from tablet 7b; and C-1 (30 min), C-2 (90 min), and C-3 (300 min) were taken from tablet $8 \mathrm{~b}$ ingestion. Dotted circles indicate the presence of ingested barium-containing tablets.

Additionally, we observed the glucose content for five hours in total (data not shown), and no increases were found after three hours, which means that the $\mathrm{AUC}_{0-180 \mathrm{~min}}$ and $\mathrm{AUC}_{0-300 \min }$ were equivalent for all the tablets. The three $\mathrm{T}_{\max }$ values were also approximately the same. These data imply that glucose may leak from the tablets through the shellac layer in the stomach or the duodenum; otherwise, the $T_{\max }$ values would have differed among the three tableting formulations. As mentioned above, a similar phenomenon was observed in the X-ray photographical study, and the brittleness of the coating film in the gastric tract is one possible explanation for the leak. 


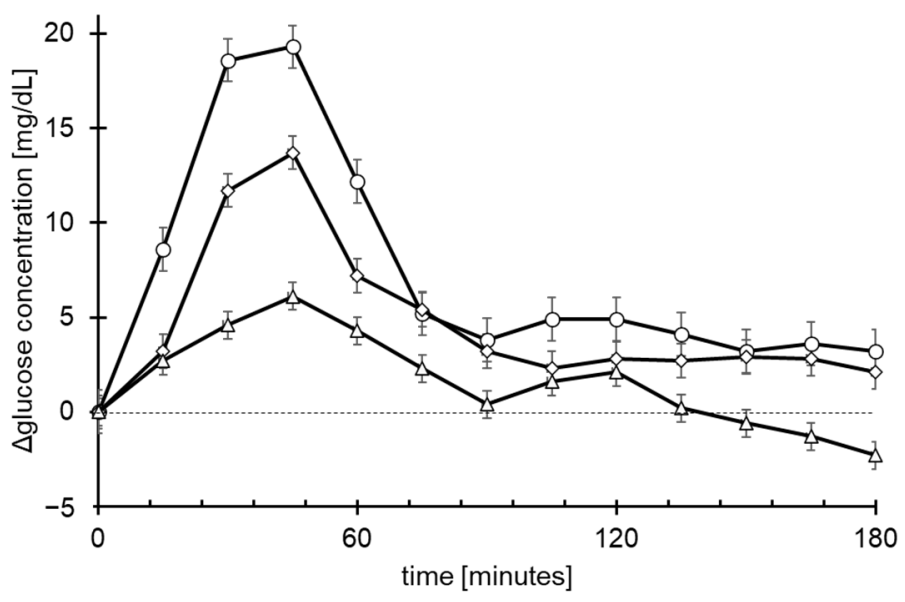

Figure 4. Changes in glucose concentration in cell interstitial fluid obtained from the volunteer study. Data are expressed as open circles for tablet 9, open squares for tablet 10, and open triangles for tablet 11 , and each group consisted of the same volunteers $(n=9)$. All the data represent means \pm SEs.

Table 5. Pharmacokinetic parameters of tablets 9, 10, and 11 regarding glucose concentrations obtained from the human volunteer study $(n=9)$.

\begin{tabular}{cccc}
\hline & Tablet 9 & Tablet 10 & Tablet 11 \\
\hline AUC (mg.h/L) & $276.1 \pm 35.3$ & $168.1 \pm 33.9^{*}$ & $89 \pm 30.7^{* *}$ \\
C $_{\max }$ (mg/dL) & $24.5 \pm 3.4$ & $15.6 \pm 2.5^{\#}$ & $9 \pm 2.7^{\# \#}$ \\
$\mathrm{~T}_{\max }$ (hours) & $0.6 \pm 0.1$ & $1.1 \pm 0.3$ & $0.9 \pm 0.2$
\end{tabular}

Data represent means \pm SEs $(n=9) .{ }^{*}$ denotes significant difference compared with tablet $9(p<0.05)$, and

** means $p<0.01$ in the AUC analysis. \# denotes significant difference compared with tablet $9(p<0.05)$, and

\#\# means $p<0.01$ in the $C_{\max }$ analysis. Significant differences between tablets 10 and 11 were not found in the three analyses.

\section{Conclusions}

A new gastrointestinal delivery system was developed, employing HPMC and a shellac coating. Its delivery function was herein demonstrated through human studies for the first time. The present study provides one of the possibilities for delivering drug compounds and/or food components to the gastrointestinal tract; however, further studies including several compounds in the delivery system are needed to clarify the actual therapeutic effects, because each compound generally possesses particular properties that affect its absorbability, such as solubility, membrane permeability, absorbable area, and effective dose. Following future studies, this system may be utilized for pharmaceutical products as well as food supplements; it would especially provide much opportunity to investigate the biological benefits of food ingredients delivered to the lower intestine or the colon in human and companion animals and to develop several health-beneficial products, since few materials are available for formulations of intestinal delivery systems in food supplements.

Author Contributions: Conceptualization, J.W., K.U., and I.M.; Methodology, J.W. and K.S.; Formal analysis, J.W. and K.S.; Investigation, J.W. and K.S.; Writing—original draft preparation, J.W. and I.M.; Writing-review and editing, J.W., K.S., K.U., and I.M.; All authors have read and agreed to the published version of the manuscript.

Funding: This research received no external funding.

Institutional Review Board Statement: The human studies were conducted according to the guidelines of the Declaration of Helsinki and approved by the Ethics Committee organized by User Life Science Co., Ltd., (Fukuoka, Japan). The details are described in the manuscript. 
Informed Consent Statement: Informed consent was obtained from all the subjects involved in the study.

Data Availability Statement: The datasets used and/or analyzed during the current study are available from the corresponding author on reasonable request.

Acknowledgments: We would like to thank Tomie Shimizu and Hideki Shono for their special encouragement of this research. We express great gratitude to Wakana Hirano, Takahiro Iizuka, and all the members of the R\&D division for their daily support. Additionally, we deeply appreciate Koichiro Ohnuki for his fruitful advice and organization of the clinical studies.

Conflicts of Interest: The authors declare no conflict of interest.

\section{References}

1. GRAND VIEW RESEARCH. Available online: https:/ /www.grandviewresearch.com/industry-analysis/dietary-supplementsmarket (accessed on 30 June 2021).

2. Fujii, T.; Jounai, K.; Horie, A.; Takahashi, H.; Suzuki, H.; Ohshio, K.; Fujiwara, D.; Yamamoto, N. Effects of heat-killed Lactococcus lactis subsp. lactis JCM 5805 on mucosal and systemic immune parameters, and antiviral reactions to influenza virus in healthy adults; a randomized controlled double-blind study. J. Funct. Foods 2017, 35, 513-521. [CrossRef]

3. Sourav, D.; Sharat, S.; Lyndem, S.; Roy, A.S. An investigation into the identification of potential inhibitors of SARS-CoV-2 main protease using molecular docking study. J. Biomol. Struct. Dyn. 2020, 39, 3347-3357.

4. Piao, Z.-Z.; Lee, K.-H.; Kim, N.-J.; Lee, H.-G.; Lee, J.; Oh, K.T.; Lee, B.-J. Comparison of release-controlling efficiency of polymeric coating materials using matrix-type casted films and diffusion-controlled coated tablet. AAPS PharmSciTech 2010, 11, 630-636. [CrossRef]

5. Kim, M.S.; Kim, J.S.; Kang, S.H.; Yoo, Y.H.; Lee, S.; Park, J.S.; Woo, J.S.; Hwang, S.J. Influence of water soluble additives and HPMCP on drug release from surelease ${ }^{\circledR}$-coated pellets containing tamsulosin hydrochloride. Arch. Pharm. Res. 2007, 30, 1008-1013. [CrossRef] [PubMed]

6. Chen, L.; Yang, G.; Chu, X.; Gao, C.; Wang, Y.; Gong, W.; Li, Z.; Yang, Y.; Yang, M.; Gao, C. Polymer distribution and mechanism conversion in multiple media of phase-separated controlled-release film-coating. Pharmaceutics 2019, 11, 80. [CrossRef] [PubMed]

7. Obeidat, W.M.; Nokhodchi, A.; Alkhatib, H. Evaluation of matrix tablets based on eudragit ${ }^{\circledR}$ E100/carbopol ${ }^{\circledR} 971 \mathrm{P}$ combinations for controlled release and improved compaction properties of water soluble model drug paracetamol. AAPS PharmSciTech 2015, 16, 1169-1179. [CrossRef]

8. Sahoo, J.; Murthy, P.N.; Biswal, S.; Sahoo, S.K.; Mahapatra, A.K. Comparative study of propranolol hydrochloride release from matrix tablets with Kollidon ${ }^{\circledR}$ SR or hydroxy propyl methyl cellulose. AAPS PharmSciTech 2008, 9, 577-582. [CrossRef]

9. Cao, Q.-R.; Choi, Y.-W.; Cui, J.-H.; Lee, B.-J. Formulation, release characteristics and bioavailability of novel monolithic hydroxypropylmethylcellulose matrix tablets containing acetaminophen. J. Control. Release 2005, 108, 351-361. [CrossRef]

10. Kibria, G.; Roni, M.A.; Absar, M.S.; Jalil, R.-U. Effect of plasticizer on release kinetics of diclofenac sodium pellets coated with eudragit RS 30 D. AAPS PharmSciTech 2008, 9, 1240-1246. [CrossRef]

11. Phaechamud, T.; Ritthidej, G.C. Formulation variables influencing drug release from layered matrix system comprising chitosan and xanthan gum. AAPS PharmSciTech 2008, 9, 870-877. [CrossRef]

12. Maity, S.; Sa, B. Compression-coated tablet for colon targeting: Impact of coating and core materials on drug release. AAPS PharmSciTech 2015, 17, 504-515. [CrossRef]

13. Lee, B.-J.; Ryu, S.-G.; Cui, J.-H. Controlled release of dual drug-loaded hydroxypropyl methylcellulose matrix tablet using drug-containing polymeric coatings. Int. J. Pharm. 1999, 188, 71-80. [CrossRef]

14. He, W.; Huang, S.; Zhou, C.; Cao, L.; Yao, J.; Zhou, J.; Wang, G.; Yin, L. Bilayer matrix tablets for prolonged actions of metformin hydrochloride and repaglinide. AAPS PharmSciTech 2014, 16, 344-353. [CrossRef] [PubMed]

15. EI Naggar, E.E.; Mohamed, E.A.; Borg, T.M.; EI-Sheakh, A.R.; Harmed, M.F. Colon targeting of naringin for enhanced cytoprotection against indomethacin-induced colitis in rabbits. Drug Des. Devel. Ther. 2020, 14, 677-696. [CrossRef] [PubMed]

16. Al-Gousous, J.; Penning, M.; Langguth, P. Molecular insights into shellac film coats from different aqueous shellac salt solutions and effect on disintegration of enteric-coated soft gelatin capsules. Int. J. Pharm. 2015, 484, 283-291. [CrossRef] [PubMed]

17. Farag, Y.; Leopold, C.S. Development of shellac-coated sustained release pellet formulations. Eur. J. Pharm. Sci. 2011, 42, 400-405. [CrossRef]

18. Oehme, A.; Valotis, A.; Krammer, G.; Zimmermann, I.; Schreier, P. Preparation and characterization of shellac-coated anthocyanin pectin beads as dietary colonic delivery system. Mol. Nutr. Food Res. 2011, 55, S75-S85. [CrossRef] [PubMed]

19. Peppas, N.A.; Sahlin, J.J. A simple equation for the description of solute release. III. Coupling of diffusion and relaxation. Int. J. Pharm. 1989, 57, 169-172. [CrossRef]

20. Korsmeyer, R.W.; Gurny, R.; Doelker, E.; Buri, P.; Peppas, N.A. Mechanisms of solute release from porous hydrophilic polymers. Int. J. Pharm. 1983, 15, 25-35. [CrossRef]

21. Limmatvapirat, S.; Limmatvapirat, C.; Puttipipatkhachorn, S.; Nuntanid, J.; Luangtana-Anan, M. Enhanced enteric properties and stability of shellac films through composite salts formation. Eur. J. Pharm. Biopharm. 2007, 67, 690-698. [CrossRef] 
22. Rujivipat, S.; Bodmeier, R. Modified release from hydroxypropyl methylcellulose compression-coated tablets. Int. J. Pharm. 2010, 402, 72-77. [CrossRef] [PubMed]

23. Koziolek, M.; Grimm, M.; Becker, D.; Lordanov, V.; Zou, H.; Shimizu, J.; Wanke, C.; Garbacz, G.; Weitschies, W. Investigation of $\mathrm{pH}$ and temperature profiles in the GI tract of fasted human subjects using the Intellicap ${ }^{\circledR}$ system. J. Pharm. Sci. 2015, 109, 2855-2863. [CrossRef] [PubMed]

24. Bailey, T.; Bode, B.W.; Christiansen, M.P.; Klaff, L.J.; Alva, S. The performance and usability of a factory-calibrated flash glucose monitoring system. Diabetes Technol. Ther. 2015, 17, 787-794. [CrossRef]

25. Wachters-Hagedoorn, R.E.; Priebe, M.G.; Heimweg, J.A.J.; Heiner, A.M.; Englyst, K.N.; Holst, J.J.; Stellaard, F.; Vonk, R.J. The rate of intestinal glucose absorption is correlated with plasma glucose-dependent insulinotropic polypeptide concentrations in healthy men. J. Nutr. 2006, 136, 1511-1516. [CrossRef] [PubMed] 